\title{
GLP-1 Based Combination Therapy for Obesity and Diabetes
}

\author{
Young Hee Lee ${ }^{1,2}$, Hee Won Lee ${ }^{1}$, Hyung Jin Choi ${ }^{1,2,3,4,5, *}$ \\ ${ }^{1}$ Functional Neuroanatomy of Metabolism Regulation Laboratory, Department of Anatomy; ${ }^{2}$ Department of Anatomy \\ and Cell Biology, Seoul National University College of Medicine, Seoul; ${ }^{3}$ BK21Plus Biomedical Science Project Team; \\ ${ }^{4}$ Neuroscience Research Institute, Seoul National University College of Medicine, Seoul; ${ }^{5}$ Wide River Institute of \\ Immunology, Seoul National University, Hongcheon, Korea
}

\author{
${ }^{*}$ Corresponding author \\ Hyung Jin $\mathrm{Choi}^{1,2}$ \\ http://orcid.org/0000-0003-0593-6978 \\ ${ }^{1}$ Department of Biomedical Sciences \\ ${ }^{2}$ Department of Anatomy, Seoul National \\ University College of Medicine, 101 \\ Daehak-ro, Jongno-gu, Seoul 03080, \\ Korea \\ Tel: +82-2-740-8204 \\ Fax: +82-2-745-9528 \\ E-mail: hjchoi@snu.ac.kr
}

\section{INTRODUCTION}

Obesity and its comorbidities, such as type 2 diabetes, are major public health diseases in modern society. Despite the currently significant unmet needs of type 2 diabetes patients, effective and safe pharmacological treatments that deliver adequate weight loss and glucose control have not been discovered.

Anorectic gut hormone, glucagon-like peptide 1 (GLP-1), is widely used to treat obesity and diabetes. ${ }^{1,2}$ GLP-1 is a type of incretin released from the $\mathrm{L}$ cells of the large intestine and distal ileum when nutrients contact the intestine. In rodents and humans, GLP-1 receptor (GLP-1R) is expressed in many tissues including $\alpha, \beta$, and $\delta$ cells of the pancreatic islets, lung, heart, kidney, stomach, intestine, pituitary, skin, nodose ganglion neurons of the vagus nerve and several regions of the central nervous system including the hypothalamus and brainstem. ${ }^{3}$ The GLP-1 agonist, Exendin-4, has been shown to reduce food intake by slowing gastric emptying and increasing satiety. ${ }^{4-9}$ GLP-1 exhibits an anti-diabetic effect in addition to the above-mentioned anti-obesity effect. GLP-1 potentiates glucose-stimulated insulin secretion and enhances glucose homeostasis. GLP-1 agonists usually provide significant weight reduction and glucose improvement, but only a few patients achieve adequate weight/glucose control and often experience dose-limiting adverse effects such as nausea and risk of pancreatitis.

Therefore, many researchers pursue novel therapeutics that combine GLP-1/GLP-1 agonists with other peptides such as gastric inhibitory polypeptide (GIP), glucagon and peptide YY (PYY) (Table 1). Effective combination drugs may produce synergistic effects by targeting multi-organ mechanisms (Fig. 1). In this editorial, we discuss the preclinical and clinical studies on GLP-1-based combination therapies for obesity and diabetes.

\section{GLP-1 and GIP}

GIP is a gut hormone synthesized by $\mathrm{K}$ cells in the mucosa of the duodenum and the jejunum of the gastrointestinal tract by binding to gastric inhibitory polypeptide receptor. Several studies have investigated the combination effects of GLP-1 and GIP on metabolic diseases. Central co-administration of GLP-1 and GIP synergistically decreased food intake and body weight. ${ }^{10}$ Central GLP-1 and GIP co-administration significantly increased neuronal activation and pro-opiomelanocortin expression in the arcuate nucleus of the hypothalamus compared to GLP-1 or GIP alone. Peripheral co-administration of GLP-1 and GIP were investigated in several studies. When a GLP-1 or GIP analog was administered intraperitoneally to diet-induced obese 
Table 1. Preclinical and clinical results of GLP-1-based combination therapies for obesity and diabetes

\begin{tabular}{|c|c|c|c|c|c|c|c|}
\hline \multirow{2}{*}{ Combination drug } & \multirow{2}{*}{ Subjects } & \multirow{2}{*}{ Route } & \multicolumn{3}{|c|}{ Anti-obesity } & \multirow{2}{*}{$\frac{\text { Anti-diabetes }}{\text { Glucose tolerance }}$} & \multirow{2}{*}{ Reference } \\
\hline & & & Food intake & Body weight & Energy expenditure & & \\
\hline GIP & Mice & Central ICV & $\downarrow$ & $\downarrow$ & - & - & NamKoong et al. $(2017)^{10}$ \\
\hline GLP-1/GIP & DIO & S.C. & $\downarrow$ & $\downarrow$ & - & $\uparrow$ & Finan et al. (2013)11 \\
\hline co-agonist & Mice & & & & & & \\
\hline $\begin{array}{l}\text { GLP-1/GIP } \\
\text { co-agonist }\end{array}$ & Monkeys & S.C. & - & - & - & $\uparrow$ & Finan et al. $(2013)^{11}$ \\
\hline $\begin{array}{l}\text { GLP-1/GIP } \\
\text { co-agonist }\end{array}$ & $\begin{array}{l}\text { Lean } \\
\text { Male } \\
\text { Rats }\end{array}$ & S.C. & - & - & - & $\uparrow$ & Finan et al. $(2013)^{11}$ \\
\hline $\begin{array}{l}\text { GLP-1/GIP } \\
\text { co-agonist }\end{array}$ & $\begin{array}{l}\text { Healthy/ } \\
\text { T2DM } \\
\text { Humans }\end{array}$ & S.C. & - & - & - & $\uparrow$ & Finan et al. $(2013)^{11}$ \\
\hline Lira-AcGIP & $\begin{array}{l}\text { Swiss T0 } \\
\text { Mice }\end{array}$ & $\mathbb{P}$ & - & - & - & $\uparrow$ & Gault et al. $(2011)^{12}$ \\
\hline Lira-AcGIP & $\begin{array}{l}\text { ob/ob } \\
\text { Mice }\end{array}$ & $\mathbb{P}$ & $\downarrow$ & $\downarrow$ & - & $\uparrow$ & Gault et al. $(2011)^{12}$ \\
\hline N-AcGIP & $\begin{array}{l}\text { HFD } \\
\text { Mice }\end{array}$ & S.C. & $\downarrow$ & $\downarrow$ & - & $\uparrow$ & Frias et al. $(2017)^{13}$ \\
\hline Glucagon & $\begin{array}{l}\text { DIO } \\
\text { Mice }\end{array}$ & S.C. & $\downarrow$ & $\downarrow$ & $\uparrow$ & $\uparrow$ & Day et al. $(2009)^{14}$ \\
\hline Glucagon & $\begin{array}{l}\text { Obese } \\
\text { Humans }\end{array}$ & IV & $\downarrow$ & - & $\uparrow$ & - & Cegla et al. $(2014)^{15}$ \\
\hline Glucagon & $\begin{array}{l}\text { Obese } \\
\text { Humans }\end{array}$ & IV & - & - & $\uparrow$ & - & Tan et al. $(2013)^{16}$ \\
\hline GLP1/GIP/Glucagon triagonist & $\begin{array}{l}\text { DIO } \\
\text { Mice }\end{array}$ & S.C. & $\downarrow$ & $\downarrow$ & $\uparrow$ & $\uparrow$ & Finan et al. $(2015)^{17}$ \\
\hline GLP1/GIP/Glucagon triagonist & $\begin{array}{l}\text { HFD } \\
\text { Mice }\end{array}$ & $\mathbb{P}$ & $\leftrightarrow$ & $\downarrow$ & - & $\uparrow$ & Gault et al. $(2013)^{18}$ \\
\hline PYY & $\begin{array}{l}\text { Healthy } \\
\text { Humans }\end{array}$ & IV & $\downarrow$ & - & - & - & De Silva et al. $(2011)^{23}$ \\
\hline PYY 3-36 & $\begin{array}{l}\text { Healthy } \\
\text { Humans }\end{array}$ & PO & $\downarrow$ & - & - & - & Steinert et al. $(2010)^{24}$ \\
\hline PYY 3-36 & Mice & $\mathbb{I P}$ & $\downarrow$ & $\leftrightarrow$ & - & - & Talsania et al. $(2005)^{25}$ \\
\hline CCK-33 & $\begin{array}{l}\text { Healthy } \\
\text { Humans }\end{array}$ & IV & $\downarrow$ & - & - & - & Gutzwiller et al. (2004) ${ }^{26}$ \\
\hline Leptin & Rats & $\mathbb{P}$ & $\downarrow$ & - & - & - & Akieda-Asai et al. (2014) ${ }^{27}$ \\
\hline Leptin & Rats & $\mathbb{P}$ & $\downarrow$ & $\downarrow$ & - & - & Bojanowska et al. $(2007)^{28}$ \\
\hline Naltrexone (Opioid antagonist) & Rats & $\mathbb{P}$ & $\downarrow$ & - & - & - & Liang et al. $(2013)^{29}$ \\
\hline Salmon Calcitonin (Amylin analog) & Monkeys & Intramuscular & $\downarrow$ & - & - & - & Bello et al. $(2010)^{30}$ \\
\hline Gastrin & $\begin{array}{l}\mathrm{db} / \mathrm{db} \\
\text { Mice }\end{array}$ & $\mathbb{P}$ & - & - & - & - & Tamaki et al. $(2010)^{32}$ \\
\hline Gastrin & Mice & $\mathbb{P}$ & - & - & - & - & Suarez-Pinzon et al. $(2008)^{33}$ \\
\hline
\end{tabular}

GLP-1, glucagon-like peptide 1; GIP, gastric inhibitory polypeptide; ICV, intracerebral ventricular; DIO, diet-induced obesity; S.C., subcutaneous; T2DM, type 2 diabetes; AcGIP, acylated gastric inhibitory polypeptide; TO, tuck ordinary; IP, intraperitoneal injection; HFD, high fat diet; PYY, peptide YY; IV, intravenous; PO, per os; CCK, cholecystokinin.

(DIO) mice, the GLP-1 analog decreased body weight (15.4\%). ${ }^{11}$ A comparable dose of the GIP analog did not cause significant metabolic improvements. However, co-administration of GLP-1 and GIP decreased fat mass and body weight (20.8\%) and reduced food intake more than GLP-1 or GIP alone. Based on the enhanced efficacy of GLP-1 and GIP co-administration, a singlemolecule GLP-1/GIP co-agonist was investigated. This acylated co-agonist or liraglutide (an acylated GLP-1 analog) was administered to DIO mice for 4 weeks. The treatment with unimolecular co-agonist resulted in greater metabolic improvements than a 


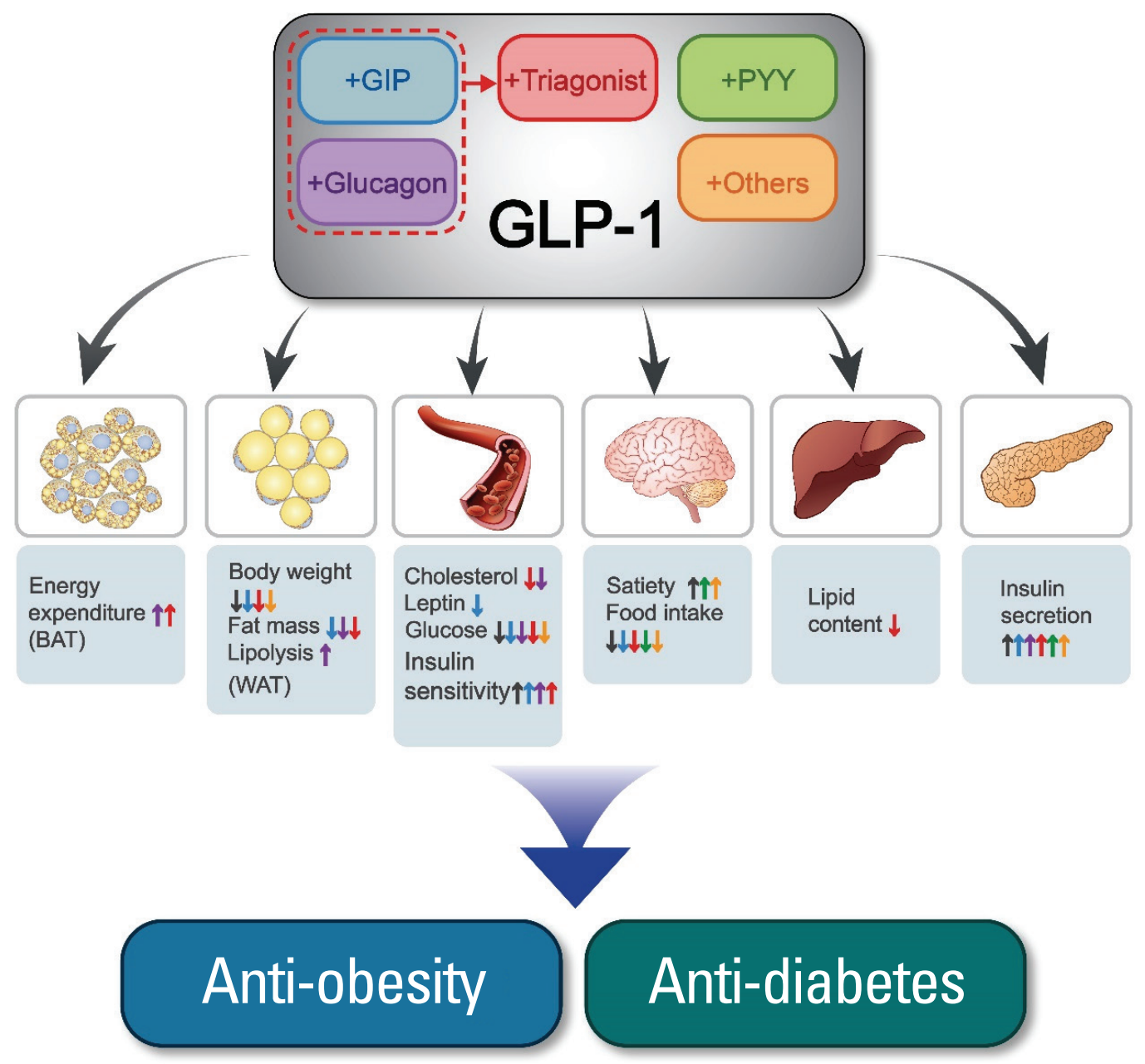

Figure 1. Metabolic actions of GLP-1-based combination therapy on major organs (BAT, WAT, circulation, brain, liver and pancreas). GIP, gastric inhibitory polypeptide; PYY, peptide YY; GLP-1, glucagon-like peptide 1; BAT, brown adipose tissue; WAT, white adipose tissue.

similar dose of liraglutide. The enhanced insulinotropic effect of unimolecular dual incretins was also observed in nonhuman primates. Enhanced insulin secretory response in cynomolgus monkeys increased plasma insulin and C-peptide. In human studies, unimolecular dual incretin treatment caused rapid and significant decrease in $\mathrm{HbAlc}$ (hemoglobin Alc) without vomiting and minimal adverse effects. In another study, acylated analogs of GLP-1 and GIP were shown to affect weight loss, modify plasma glucose level and significantly modify insulin responses in mice with diabetes. ${ }^{12}$ In a recent study, dual unimolecular incretins (fatty-acylated GLP-1/GIP receptor agonist) significantly reduced HbAlc, cholesterol, leptin and body weight in patients with type 2 diabetes. ${ }^{13}$ Based on mouse, non-human primate and human studies, the combination of GLP-1 and GIP showed promising potential for anti-obesity and anti-diabetic therapies.

\section{GLP-1 and glucagon}

Glucagon and GLP-1 are the first products produced when proglucagon is processed in the pancreas and gut, respectively. Glucagon is secreted by a cells of the pancreas, binds to receptors mainly expressed on liver and kidney and increases blood glucose levels by activating hepatic glucose production. Preclinical studies in DIO mice showed the administration of glucagon/GLP-1 co-agonist normalized adiposity by activating white adipose tissue (WAT) lipolysis and increased insulin sensitivity and glucose tolerance..$^{14}$ Acute co-infusion of low doses of GLP-1 and native glucagon increased energy expenditure synergistically. ${ }^{15}$ Experiments performed in humans indicated the combination of gluca- 
gon and GLP-1 synergistically increases resting energy expenditure and insulin level. ${ }^{16}$ In both preclinical and clinical studies, the combination of GLP-1 and glucagon showed anti-diabetic and anti-obesity synergistic effects.

\section{Unimolecular GLP-1/GIP/glucagon triagonist}

Due to recently developed high-technology approaches, research focusing on unimolecular co-agonists is currently being conducted. In particular, the 3 hormones, GLP-1, GIP and glucagon, have unique enteroinsular effects as well as roles in the regulation of energy and glucose homeostasis. Several studies reported the unimolecular, balanced, GLP-1/GIP/glucagon triagonist is superior to the respective dual agonists. ${ }^{17,18}$ At a low dose, liraglutide and the GIP/glucagon co-agonist did not improve body weight, whereas triagonist decreased body weight by $15.1 \% .^{17}$ The co-agonist and the triagonist were both equally effective in improving glucose tolerance and decreasing ad libitum-fed blood glucose without hypoglycemia. However, the triagonist decreased the plasma concentrations of insulin more than the coagonists, indicating insulin sensitivity improved more with a triagonist than with a co-agonist. Furthermore, the triagonist lowered the circulating concentration of cholesterol thus lowering hepatic lipid content and hepatocellular vacuolation. Enhanced energy expenditure was also observed in triagonist-treated DIO mice compared with pair-fed controls. In another study, GLP-1/ GIP/glucagon triagonist decreased body weight, exerted insulin secretory actions and improved both glucose tolerance and insulin resistance in mice fed a high-fat diet. ${ }^{18}$ Collectively, these preclinical studies showed the triagonist of incretin components has anti-obesity and anti-diabetes potential.

\section{GLP-1 and PYY}

PYY is secreted with GLP-1 in the L cells of the distal gut after nutrient ingestion to reduce appetite and food intake. GLP-1 and PYY bind to GLP-1R and neuropeptide Y2-receptor, respectively. ${ }^{19,20}$ Both receptors are found in the arcuate nucleus of the hypothalamus, dorsal vagal complex, nucleus tractus solitarii, area postrema and nodose ganglion of the vagus nerve. ${ }^{21,22}$ When PYY and GLP-1 were administered together intravenously to fasted humans, energy intake was reduced and activity in several areas of the brain involved in response to satiety increased. ${ }^{23} \mathrm{Co}$-administration of both peptides to humans induced pre-meal insulin secretion. ${ }^{24}$ Preclinical studies in mice showed that systemic co-administration of PYY and Exendin-4, a long acting GLP-1, synergistically decreased appetite and food intake independent of the GLP-1R signaling pathway. ${ }^{25}$ In clinical and preclinical studies, the combination of GLP-1 and PYY demonstrated anti-obesity effects.

\section{GLP-1 and other combinations}

Several other combinations, including leptin, calcitonin, naltrexone, cholecystokinin (CCK) or gastrin with GLP-1, have been investigated for anti-obesity and anti-diabetic effects. CCK is a typical gastrointestinal hormone that promotes satiety after eating. When CCK is infused with GLP-1 to healthy humans, hunger feelings were synergistically reduced before meals. ${ }^{26}$ Leptin is an anorectic hormone secreted by WAT by binding to the leptin receptor. Intraperitoneal co-administration of GLP-1 and leptin significantly reduced food intake in rats by transmitting the anorectic signal via the ascending neural pathway from the hindbrain. ${ }^{27}$ The combination of Exendin- 4 and leptin showed an additive effect on food intake reduction. ${ }^{28}$ Naltrexone is an opioid antagonist acting on the reward system. The combination of naltrexone and Exendin-4 synergistically suppressed food intake in a dose-dependent manner and resulted in a rapid acquisition of a conditioned taste aversion. ${ }^{29}$ Amylin is a pancreatic peptide co-secreted with insulin and involved in the control of satiety signaling. The combination of Exendin-4 and an amylin analog, salmon calcitonin, elicited a synergistic effect on reducing food intake and produced body weight loss in monkeys. ${ }^{30}$ Gastrin is a peptide hormone secreted primarily by $\mathrm{G}$ cells in response to food ingestion and acts on its receptor, cholecystokinin $B$ receptor, to exert physiological actions in the colon, pancreas, small intestine, liver, esophagus and kidney. ${ }^{31}$ The combined administration of Exendin-4 with gastrin to diabetic $\mathrm{db} / \mathrm{db}$ mice promoted $\beta$ cell proliferation and differentiation, thereby maintaining the mass of $\beta$ cells. ${ }^{32}$ Combination therapy with GLP-1 and gastrin restored normoglycemia in non-obese diabetic mice by increasing the pancreatic $\beta$ cell mass and downregulating the autoimmune response. ${ }^{33}$ 


\section{CONCLUSION}

Many recent reports demonstrated that synergism with GLP-1 pharmacology, in contrast to existing monotherapies, has provided distinct novel strategies to combat multiple mechanisms simultaneously. Most of the current literature on GLP-1 combination therapies focused only on food intake. Only a few studies investigated the effect of GLP-1 combination therapy on energy expenditure, another major mechanism underlying obesity treatment. The role of GLP-1 combination therapy on energy expenditure should be clarified in future studies. Novel GLP-1 combination strategies with other anti-obesity and anti-diabetic hormones or drugs could produce more diverse multifunctional, targeted therapeutics. Through these efforts, GLP-1-based combination strategies will provide diverse therapeutic options and open a new era for personalized obesity and diabetes treatments.

\section{CONFLICTS OF INTEREST}

The authors declare no conflict of interest.

\section{ACKNOWLEDGMENTS}

The authors would like to thank Ms. Sun Joo Kim for the preparation of the excellent illustrations and graphic design.

\section{REFERENCES}

1. Brubaker PL, Drucker DJ. Minireview: Glucagon-like peptides regulate cell proliferation and apoptosis in the pancreas, gut, and central nervous system. Endocrinology 2004;145:2653-9.

2. Mojsov S, Kopczynski MG, Habener JF. Both amidated and nonamidated forms of glucagon-like peptide I are synthesized in the rat intestine and the pancreas. J Biol Chem 1990;265: 8001-8.

3. Baggio LL, Drucker DJ. Biology of incretins: GLP-1 and GIP. Gastroenterology 2007;132:2131-57.

4. Hayes MR, Skibicka KP, Grill HJ. Caudal brainstem processing is sufficient for behavioral, sympathetic, and parasympathetic responses driven by peripheral and hindbrain glucagon- like-peptide-1 receptor stimulation. Endocrinology 2008;149: 4059-68.

5. Kinzig KP, D’Alessio DA, Seeley RJ. The diverse roles of specific GLP-1 receptors in the control of food intake and the response to visceral illness. J Neurosci 2002;22:10470-6.

6. Mack CM, Moore CX, Jodka CM, Bhavsar S, Wilson JK, Hoyt JA, et al. Antiobesity action of peripheral exenatide (exendin-4) in rodents: effects on food intake, body weight, metabolic status and side-effect measures. Int J Obes (Lond) 2006; 30:1332-40.

7. Nagell CF, Wettergren A, Ørskov C, Holst JJ. Inhibitory effect of GLP-1 on gastric motility persists after vagal deafferentation in pigs. Scand J Gastroenterol 2006;41:667-72.

8. Verdich C, Flint A, Gutzwiller JP, Näslund E, Beglinger C, Hellström PM, et al. A meta-analysis of the effect of glucagonlike peptide-1 (7-36) amide on ad libitum energy intake in humans. J Clin Endocrinol Metab 2001;86:4382-9.

9. Williams DL, Baskin DG, Schwartz MW. Evidence that intestinal glucagon-like peptide-1 plays a physiological role in satiety. Endocrinology 2009; 150:1680-7.

10. NamKoong C, Kim MS, Jang BT, Lee YH, Cho YM, Choi HJ. Central administration of GLP-1 and GIP decreases feeding in mice. Biochem Biophys Res Commun 2017;490:247-52.

11. Finan B, Ma T, Ottaway N, Müller TD, Habegger KM, Heppner KM, et al. Unimolecular dual incretins maximize metabolic benefits in rodents, monkeys, and humans. Sci Transl Med 2013;5:209ra151.

12. Gault VA, Kerr BD, Harriott P, Flatt PR. Administration of an acylated GLP-1 and GIP preparation provides added beneficial glucose-lowering and insulinotropic actions over single incretins in mice with type 2 diabetes and obesity. Clin Sci (Lond) 2011;121:107-17.

13. Frias JP, Bastyr EJ 3rd, Vignati L, Tschöp MH, Schmitt C, Owen $\mathrm{K}$, et al. The sustained effects of a dual GIP/GLP-1 receptor agonist, NNC0090-2746, in patients with type 2 diabetes. Cell Metab 2017;26:343-52.e2.

14. Day JW, Ottaway N, Patterson JT, Gelfanov V, Smiley D, Gidda J, et al. A new glucagon and GLP-1 co-agonist eliminates obesity in rodents. Nat Chem Biol 2009;5:749-57.

15. Cegla J, Troke RC, Jones B, Tharakan G, Kenkre J, Mc- 
Cullough KA, et al. Coinfusion of low-dose GLP-1 and glucagon in man results in a reduction in food intake. Diabetes 2014;63:3711-20.

16. Tan TM, Field BC, McCullough KA, Troke RC, Chambers ES, Salem V, et al. Coadministration of glucagon-like peptide-1 during glucagon infusion in humans results in increased energy expenditure and amelioration of hyperglycemia. Diabetes 2013;62:1131-8.

17. Finan B, Yang B, Ottaway N, Smiley DL, Ma T, Clemmensen C, et al. A rationally designed monomeric peptide triagonist corrects obesity and diabetes in rodents. Nat Med 2015;21:27-36.

18. Gault VA, Bhat VK, Irwin N, Flatt PR. A novel glucagon-like peptide-1 (GLP-1)/glucagon hybrid peptide with triple-acting agonist activity at glucose-dependent insulinotropic polypeptide, GLP-1, and glucagon receptors and therapeutic potential in high fat-fed mice. J Biol Chem 2013;288:35581-91.

19. Batterham RL, Cowley MA, Small CJ, Herzog H, Cohen MA, Dakin CL, et al. Gut hormone PYY(3-36) physiologically inhibits food intake. Nature 2002;418:650-4.

20. Turton MD, O’Shea D, Gunn I, Beak SA, Edwards CM, Meeran $\mathrm{K}$, et al. A role for glucagon-like peptide- 1 in the central regulation of feeding. Nature 1996;379:69-72.

21. Campos RV, Lee YC, Drucker DJ. Divergent tissue-specific and developmental expression of receptors for glucagon and glucagon-like peptide-1 in the mouse. Endocrinology 1994; 134:2156-64.

22. Gustafson EL, Smith KE, Durkin MM, Walker MW, Gerald C, Weinshank R, et al. Distribution of the neuropeptide Y Y2 receptor mRNA in rat central nervous system. Brain Res Mol Brain Res 1997;46:223-35.

23. De Silva A, Salem V, Long CJ, Makwana A, Newbould RD, Rabiner EA, et al. The gut hormones PYY 3-36 and GLP-1 7-36 amide reduce food intake and modulate brain activity in appetite centers in humans. Cell Metab 2011;14:700-6.

24. Steinert RE, Poller B, Castelli MC, Drewe J, Beglinger C. Oral administration of glucagon-like peptide 1 or peptide YY 3-36 affects food intake in healthy male subjects. Am J Clin Nutr 2010;92:810-7.

25. Talsania T, Anini Y, Siu S, Drucker DJ, Brubaker PL. Peripheral exendin-4 and peptide YY(3-36) synergistically reduce food intake through different mechanisms in mice. Endocrinology 2005;146:3748-56.

26. Gutzwiller JP, Degen L, Matzinger D, Prestin S, Beglinger C. Interaction between GLP-1 and CCK-33 in inhibiting food intake and appetite in men. Am J Physiol Regul Integr Comp Physiol 2004;287:R562-7.

27. Akieda-Asai S, Poleni PE, Hasegawa K, Date Y. Role of the neural pathway from hindbrain to hypothalamus in interaction of GLP1 and leptin in rats. J Endocrinol 2014;220:109-16.

28. Bojanowska E, Nowak A. Interactions between leptin and exendin-4, a glucagon-like peptide-1 agonist, in the regulation of food intake in the rat. J Physiol Pharmacol 2007;58:349-60.

29. Liang NC, Bello NT, Moran TH. Additive feeding inhibitory and aversive effects of naltrexone and exendin- 4 combinations. Int J Obes (Lond) 2013;37:272-8.

30. Bello NT, Kemm MH, Ofeldt EM, Moran TH. Dose combinations of exendin-4 and salmon calcitonin produce additive and synergistic reductions in food intake in nonhuman primates. Am J Physiol Regul Integr Comp Physiol 2010;299: R945-52.

31. Koh TJ. Extragastric effects of gastrin gene knock-out mice. Pharmacol Toxicol 2002;91:368-74.

32. Tamaki M, Fujitani Y, Uchida T, Hirose T, Kawamori R, Wata$\mathrm{da} \mathrm{H}$. Combination treatment of $\mathrm{db} / \mathrm{db}$ mice with exendin -4 and gastrin preserves $\beta$-cell mass by stimulating $\beta$-cell growth and differentiation. J Diabetes Investig 2010;1:172-83.

33. Suarez-Pinzon WL, Power RF, Yan Y, Wasserfall C, Atkinson M, Rabinovitch A. Combination therapy with glucagon-like peptide- 1 and gastrin restores normoglycemia in diabetic NOD mice. Diabetes 2008;57:3281-8. 